\section{The psychiatric impact of COVID-19 pandemic on sexual health}

Braz J Psychiatry. 2021 Jan-Feb;43(1):109

doi:10.1590/1516-4446-2020-1197

(cc) BY-NC

The new coronavirus pandemic has been considered the greatest challenge for the health system in the modern era. Although social distancing and quarantines have been necessary as public health strategies, they may contribute to psychological and mental problems. There is evidence that reduced interpersonal communication may increase the incidence of depression and anxiety and exacerbate pre-existing conditions. In fact, loneliness, denial, anxiety, depression, insomnia and despair have been reported among suspected cases of coronavirus disease (COVID19). In addition, some studies have shown an increased risk of aggressiveness and suicide in infected individuals. ${ }^{1}$

Anxiety and depression are commonly seen in men with sexual disorders such as erectile dysfunction and premature ejaculation. Anxious men are more likely to experience performance anxiety, while those with depression tend to report lack of libido. ${ }^{2}$ In female patients, depression is strongly linked to hypoactive sexual desire disorder and anxiety has been shown to interfere with arousal and the ability to achieve orgasm. Chronic dyspareunia is 3-10 times more common in women diagnosed with depression or anxiety. ${ }^{3}$

Although no published study has directly investigated changes in sexual function and behavior during COVID19, negative effects on sexual health are expected. Previous pandemics have shown that social isolation associated with fear of being infected significantly reduces sexual contact. ${ }^{1}$ Pornography consumption has also increased concomitantly with the pandemic. On March 13, 2020, the Pornhub website reported an $11.6 \%$ increase in accesses. ${ }^{4}$ Excessive masturbation can interfere in a couple's relationship, leading to growing feelings of isolation and breakups. ${ }^{5}$

The spread of COVID-19 through sexual activity is also concerning. Since the virus is present in upper airway fluids, it might be transmissible during sex. The International Society for Sexual Medicine produced a set of recommendations regarding the safety of sexual activity during the pandemic, including that healthy couples in confinement may maintain normal sexual activity. Individuals with respiratory symptoms or immunocompromised partners should abstain from sexual activity. Masturbation is safe as long as hygiene standards are maintained. Alternative sexual activity, such as exchanging messages, pictures or videos by digital means are not risky, and may even be good method for exploring a couple's sexual fantasies. 6

Therefore, COVID-19 could directly and indirectly impact the sex lives of many couples. Increasing rates of anxiety and depression may translate into higher rates of psychogenic sexual dysfunction. Protective measures to guarantee safe sex might also lead to situational difficulties, especially for those at risk of or with preexisting sexual dysfunction. The medical community must be aware of such phenomena and provide proper counseling, especially during these times, when many traditional psychological support modalities are unavailable.

Gustavo M. Paul, ${ }^{1,2}$ iD Bruno C. Nascimento, ${ }^{2,3}$ João Afif-Abdo, ${ }^{2,4}$ Francisco R. Coutinho, ${ }^{2,5}$ Eduardo $P$. Miranda, ${ }^{2,6}$ iD Carmita H.N. Abdo ${ }^{2,7}$

${ }^{1}$ Divisão de Urologia, Universidade Federal do Paraná (UFPR), Curitiba, PR, Brazil. ${ }^{2}$ Associação Brasileira de Estudos em Medicina e Saúde Sexual, Fortaleza, CE, Brazil. ${ }^{3}$ Divisão de Urologia, Universidade de São Paulo (USP), São Paulo, SP, Brazil. ${ }^{4}$ Divisão de Urologia, Hospital Santa Cruz, São Paulo, SP, Brazil. ${ }^{5}$ Divisão de Urologia, Hospital da Piedade, Rio de Janeiro, RJ, Brazil. ${ }^{6}$ Divisão de Urologia, Universidade Federal do Ceará (UFC), Fortaleza, CE, Brazil. ${ }^{7}$ Departamento de Psiquiatria, USP, São Paulo, SP, Brazil.

Submitted May 07 2020, accepted Jun 21 2020, Epub Aug 032020.

\section{Disclosure}

The authors report no conflicts of interest.

How to cite this article: Paul GM, Nascimento BC, AfifAbdo J, Coutinho FR, Miranda EP, Abdo CHN. The psychiatric impact of COVID-19 pandemic on sexual health. Braz J Psychiatry. 2021;43:109. http://dx.doi.org/ 10.1590/1516-4446-2020-1197

\section{References}

1 Lima CK, Carvalho PM, Silva Lima IA, Nunes JV, Saraiva JS, de Souza RI, et al. The emotional impact of Coronavirus 2019-nCoV (new Coronavirus disease). Psychiatry Res. 2020;287:112915.

2 Rajkumar RP, Kumaran AK. Depression and anxiety in men with sexual dysfunction: a retrospective study. Compr Psychiatry. 2015; 60:114-8.

3 Basson R, Gilks T. Women's sexual dysfunction associated with psychiatric disorders and their treatment. Womens Health (Lond). 2018;14:1745506518762664.

4 Lehmiller JJ. How the pandemic is changing pornography [Internet]. 2020 Mar 23 [cited 2020 Jun 30]. www.psychologytoday.com/ us/blog/the-myths-sex/202003/how-the-pandemic-is-changing-porno graphy

5 Duffy A, Dawson DL, das Nair R. Pornography addiction in adults: a systematic review of definitions and reported impact. J Sex Med. 2016;13:760-77.

6 International Society for Sexual Medicine (ISSM), ISSM's Communication Committee. Is it safe to have sex during the coronavirus (COVID-19) pandemic? [Internet]. [cited 2020 Jun 30]. www.issm. info/sexual-health-qa/is-it-safe-to-have-sex-during-the-coronaviruscovid-19-pandemic/ 